\title{
Responses of gross primary productivity to different sizes of precipitation events in a temperate grassland ecosystem in Inner Mongolia, China
}

\author{
GUO Qun ${ }^{1}$, LI Shenggong ${ }^{1}$, HU Zhongmin ${ }^{1 *}$, ZHAO Wei ${ }^{1,2}$, YU Guirui ${ }^{1}$, SUN Xiaomin ${ }^{1}$, LI \\ Linghao $^{3}$, LIANG Naishen ${ }^{4}$, BAI Wenming ${ }^{3}$ \\ ${ }^{1}$ Key Laboratory of Ecosystem Network Observation and Modeling, Institute of Geographic Sciences and Natural Resources \\ Research, Chinese Academy of Sciences, Beijing 100101, China; \\ ${ }^{2}$ University of Chinese Academy of Sciences, Beijing 100049, China; \\ ${ }^{3}$ State Key Laboratory of Vegetation and Environmental Change, Institute of Botany, Chinese Academy of Sciences, Beijing \\ 100093, China; \\ ${ }^{4}$ Global Carbon Cycle Research Section Center for Global Environmental Research, National Institute for Environmental \\ Studies, Tsukuba 305-8506, Japan
}

\begin{abstract}
Changes in the sizes of precipitation events in the context of global climate change may have profound impacts on ecosystem productivity in arid and semiarid grasslands. However, we still have little knowledge about to what extent grassland productivity will respond to an individual precipitation event. In this study, we quantified the duration, the maximum, and the time-integrated amount of the response of daily gross primary productivity (GPP) to an individual precipitation event and their variations with different sizes of precipitation events in a typical temperate steppe in Inner Mongolia, China. Results showed that the duration of GPP-response $\left(\tau_{\mathrm{R}}\right)$ and the maximum absolute GPP-response (GPP $\max )$ increased linearly with the sizes of precipitation events $\left(P_{\text {es }}\right)$, driving a corresponding increase in time-integrated amount of the GPP-response (GPP total) because variations of $\mathrm{GPP}_{\text {total }}$ were largely explained by $\tau_{\mathrm{R}}$ and $\mathrm{GPP}_{\max }$. The relative contributions of these two parameters to $\mathrm{GPP}_{\text {total }}$ were strongly $P_{\mathrm{es}}$-dependent. The $\mathrm{GPP}_{\max }$ contributed more to the variations of GPP total when $P_{\text {es }}$ was relatively small $(<20 \mathrm{~mm})$, whereas $I_{\mathrm{R}}$ was the main driver to the variations of GPP total when $P_{\text {es }}$ was relatively large. In addition, a threshold size of at least $5 \mathrm{~mm}$ of precipitation was required to induce a GPP-response for the temperate steppe in this study. Our work has important implications for the modeling community to obtain an advanced understanding of productivity-response of grassland ecosystems to altered precipitation regimes.
\end{abstract}

Keywords: precipitation event; grassland; gross primary productivity; global climate change; precipitation regime

Citation: GUO Qun, LI Shenggong, HU Zhongmin, ZHAO Wei, YU Guirui, SUN Xiaomin, LI Linghao, LIANG Naishen, BAI Wenming. 2016. Responses of gross primary productivity to different sizes of precipitation events in a temperate grassland ecosystem in Inner Mongolia, China. Journal of Arid Land, 8(1): 36-46. doi: 10.1007/s40333-015-0136-7

Precipitation regimes, which can be characterized by intra- and inter-annual variability of precipitation amount and the features of precipitation events (i.e. timing, size and frequency), have been expected to change locally, regionally and globally in the future (Easterling et al., 2000; Huxman et al., 2004a; Beier et al., 2012). It has been predicted by global circulation models that there would be less but larger precipitation events, and the frequency of extreme precipitation

\footnotetext{
*Corresponding author: HU Zhongmin (E-mail: huzm@igsnrr.ac.cn)

Received 2015-03-25; revised 2015-04-17; accepted 2015-07-01

(C) Xinjiang Institute of Ecology and Geography, Chinese Academy of Sciences, Science Press and Springer-Verlag Berlin Heidelberg 2016
} 
events would also increase globally in the context of global climate change (IPCC, 2013). Considering that the precipitation events are mostly of small sizes $(2-5 \mathrm{~mm}$ is the mostly frequent) in arid and semi-arid regions ( $\mathrm{Li}$ et al., 2001; Loik et al., 2004), the changes in the sizes of precipitation events may have significant consequences on productivity of grassland ecosystems because grasslands are among the most sensitive ecosystems to precipitation changes. Studies have suggested that the effects of precipitation events on productivity may be as important as the annual amount of precipitation (Swemmer et al., 2007; Walter et al., 2012). Therefore, it is imperative to study the response of productivity to different sizes of precipitation events in grassland ecosystems.

Many studies have documented that the sizes of precipitation events have strong effects on grassland productivity, however, the effects are ecosystem specific (Cherwin and Knapp, 2012; Zeppel et al., 2014). It has been reported that if the annual precipitation is predominantly composed of larger precipitation events, an increase in aboveground net primary productivity (ANPP) would be usually observed in drier environments (Heisler-White et al., 2008, 2009; Thomey et al., 2011; Huang et al., 2015), whereas a decrease of ANPP would be found in more humid environments (Knapp et al., 2002; Fay et al., 2003; Harper et al., 2005; Heisler-White et al., 2009). However, these previous studies were mostly based on the total amount of productivity of the year which primarily reflects the overall effects of all the precipitation events and their seasonal distribution, whereas the patterns of precipitation events may have great variations among years at one site or among different ecosystems. Therefore, to more precisely predict the effects of altering precipitation events on productivity, it is imperative to address how productivity responds to individual precipitation events and how this response varies with the sizes of precipitation events. Nevertheless, there is still a knowledge gap about this mainly because of the lacking of productivity data with high time resolution.

The reported productivity-response to an individual precipitation event showed that there was an ecologically effective precipitation pulse, below which the plants would have no response and only the activity of microorganisms could be enhanced (Huxman et al., 2004a; Parton et al., 2012). Studies in grasslands have suggested that the ecologically effective precipitation pulse for the response of productivity was $5 \mathrm{~mm}$ in the temperate steppe in Inner Mongolia of China (Hao et al., 2010, 2012; Zhang et al., 2013). There is also an upper limit threshold, e.g. the extreme precipitation events, above which the stimulation of productivity by precipitation events disappears (Heisler-White et al., 2008; Ross et al., 2012; Zhang et al., 2013). Previous studies have shown that plant growth and $\mathrm{CO}_{2}$ exchange increased with increasing sizes of precipitation events (Chen et al., 2009; Li et al., 2013). Although there are a lower limit and an upper limit of precipitation event sizes for the productivity-response, the shape of the relationship between the productivity-response to an individual precipitation event and the size of the precipitation event remains unclear, which is critical to modeling productivity under altering precipitation regimes in the future. Additionally, Huxman et al. (2004a) came up with a conceptual response of productivity to an individual precipitation event, in which the productivity-response could vary in terms of its duration, maximum, and time-integrated amount. Previous studies have demonstrated that inter-annual variations of gross productivity could be characterized by the length of the growing season and its maximum at daily scale (Xia et al., 2015); however, our knowledge is very limited about if the time-integrated amount could be depicted by the duration and the maximum with respect to the productivity-response to an individual precipitation event.

In this study, we quantified the response of gross primary productivity (GPP) to different sizes of precipitation events in a typical steppe in Inner Mongolia, China. Our objectives are to address two questions: (1) How much does GPP respond to an individual precipitation event in terms of its duration, maximum, and time-integrated amount? How does this response vary with the sizes of precipitation events? and (2) Is the time-integrated amount of GPP-response shaped by the duration and the maximum of the response? If this is true, what are the relative contributions of these two parameters? 


\section{Materials and methods}

\subsection{Study site}

This study was conducted in a typical steppe located near the Duolun Restoration Ecology Research Station of the Institute of Botany, Chinese Academy of Sciences $\left(42^{\circ} 02^{\prime} \mathrm{N}, 116^{\circ} 117^{\prime} \mathrm{E}\right.$; $1,324 \mathrm{~m}$ asl). Mean annual precipitation (MAP) is approximately $385.5 \mathrm{~mm}$ with the majority (over 80\%) falling in the growing season from May to September, and the pan evaporation $(1,600-1,800 \mathrm{~mm})$ is about five times higher than precipitation. Annual mean temperature is $2.1^{\circ} \mathrm{C}$, with the highest monthly mean occurring in July $\left(18.9^{\circ} \mathrm{C}\right)$ and lowest in January $\left(-17.5^{\circ} \mathrm{C}\right)$. The soil type is chestnut soil (Chinese classification) or Calcic Luvisols according to the FAO Classification (FAO, 1974), or Calcic-orthic Aridisol according to US Soil Taxonomy. The soil $\mathrm{pH}$ value is 7.12 and content of nitrogen and phosphorus are $0.17 \%$ and $0.28 \%$, respectively. The dominant plant species in this temperate steppe are Stipa krylovii Roshev., Artemisia frigid Willd., Potentilla acaulis L., Cleistogenes squarrosa (Trin.) Keng., Allium bidentatum Fisch. ex Prokh., and Agropyron cristatum (L.) Gaertn. The length of the growing season is about $150 \mathrm{~d}$, and the average plant height is about $0.4 \mathrm{~m}$. The amount of precipitation $(285 \mathrm{~mm}$ in 2012 and $262 \mathrm{~mm}$ in 2013) and the median of precipitation event size $(6.3 \mathrm{~mm}$ in 2012 and $7.7 \mathrm{~mm}$ in 2013) were similar between the two years of the measurement periods. The aboveground biomass was 151.3 $\mathrm{g} / \mathrm{m}^{2}$ in 2012 and $143.6 \mathrm{~g} / \mathrm{m}^{2}$ in 2013 , respectively. This implies that the climate and vegetation cover do not differ much between 2012 and 2013.

\subsection{Measurements}

Three plots were randomly selected in 2012. The size of each plot is $4 \mathrm{~m} \times 3 \mathrm{~m}$ with a $2-\mathrm{m}$ distance between plots. During 2012 and 2013, we measured the net ecosystem exchange (NEE) of $\mathrm{CO}_{2}$ over the steppe by a multichannel automated chamber system connected to an infrared $\mathrm{CO}_{2}$ analyzer (IRGA, Li-840, Li-Cor Inc., Nebraska, USA) and a data logger (CR3000, Campbell Scientific, Inc., Logan, UT, USA), which was developed by Dr. Liang from the National Institute for Environmental Studies of Japan (Tan et al., 2013). The automated system consists of 12 transparent PVC chambers and a control unit, and three chambers were used in this study. Each chamber has a dimension of $100 \mathrm{~cm} \times 100 \mathrm{~cm}$ and a height of $50 \mathrm{~cm}$, of which $5 \mathrm{~cm}$ is below the soil surface. There are a transparent PVC lid constructed in two halves on the top and two small side windows $(15 \mathrm{~cm} \times 25 \mathrm{~cm})$ at the two opposite sidewalls to keep good air circulation and thus minimize temperature increase during the non-measurement period. The closing and opening of the lid halves and side windows are controlled by the control unit. Two fans (KMFH-12B, Kyoei, Tokyo, Japan) are equipped inside to ensure sufficient mixing of air during the measurements. A closed-cell PVC strip $(5 \mathrm{~mm} \times 5 \mathrm{~mm})$ is attached to the edges of the underside of the lids and side windows to seal the chambers when the lids are down and the windows are closed (Liang et al., 2003). The lids and side windows are equipped with the piston of a pneumatic cylinder (MCS300, Techno Fronto, Hitachi, Japan), which are run by an air compressor. During the measurements, the chambers are closed sequentially by a homemade relay board under the control of the data logger, and then air in the closed chamber is circulated through the IRGA by a micro diaphragm pump (CM-50, Enomoto Ltd., Tokyo, Japan). The sampling period for each chamber is $150 \mathrm{~s}$ (i.e. it takes $0.5 \mathrm{~h}$ for the measurements of all the 12 chambers), and the data logger monitors output signals from the IRGA at a rate of $1 \mathrm{~Hz}$ and records their averages at 10 -s intervals. In order to exclude the effects of impure air and erratic air pressure, we rejected the data of the first $10 \mathrm{~s}$ and the last $10 \mathrm{~s}$. Finally, we got one measurement of each chamber in half an hour. NEE was calculated by the exchange rate of $\mathrm{CO}_{2}$ during the periods of measurement (i.e. $130 \mathrm{~s}$ ):

$$
\mathrm{NEE}=\left((V \times P(1-W) /(R \times S \times T)) \times\left(u_{\mathrm{c}} / u_{\mathrm{t}}\right),\right.
$$

where $V$ is the volume of the chamber $\left(\mathrm{m}^{3}\right) ; P$ is the air pressure $(\mathrm{Pa}) ; W$ is the water vapor mole fraction; $R$ is a gas constant $\left(8.314 \mathrm{~Pa} \mathrm{~m}^{3} /(\mathrm{mol} \cdot \mathrm{K})\right) ; S$ is the base area of the chamber $\left(\mathrm{m}^{2}\right) ; T$ is the air temperature in the chamber $(\mathrm{K})$; and $u_{\mathrm{c}} / u_{\mathrm{t}}$ is the rate of increase in carbon dioxide mole fraction $(\mathrm{mmol} /(\mathrm{mol} \cdot \mathrm{s}))$ in the chamber calculated by the least squares method.

Because nighttime NEE represents only ecosystem respiration (ER), we used the relationship 
between nighttime NEE and soil temperature to estimate daytime ER (Lloyd and Taylor, 1994). Further, soil water is also considered when evaluating the daytime ER because our study site has a dry environment (Reichstein et al., 2002). In this study, daytime ER was estimated by:

$$
\mathrm{ER}_{\text {daytime }}=R_{\text {eco.ref }} \times\left(b_{1}+b_{2} \mathrm{SWC}\right) \times\left(\left(T_{\mathrm{s}}-T_{\text {ref }}\right) / 10\right),
$$

where $R_{\text {eco.ref }}$ is the ecosystem respiration at reference temperature $\left(T_{\text {ref }}, 10^{\circ} \mathrm{C}\right)$ and optimal soil moisture; SWC is the soil water content; $T_{\mathrm{s}}$ is the soil temperature; $b_{1}$ and $b_{2}$ are constants evaluated from the relationship between night-time ER and temperature and SWC.

Therefore, GPP was indirectly estimated by:

$$
\mathrm{GPP}=\mathrm{ER}_{\text {daytime }}-\mathrm{NEE} \text {. }
$$

Where the negative NEE denotes a carbon flux into the steppe, whereas positive NEE denotes the reverse.

There are two self-made thermocouples in each chamber to measure air temperature and soil temperature (at a depth of $5 \mathrm{~cm}$ ) with the same time resolution as $\mathrm{CO}_{2}$ flux recorded by data logger. Volumetric soil water contents at the depths of 5,20 , and $40 \mathrm{~cm}$ were measured and calculated simultaneously at half-hourly and daily intervals by a meteorological measurement system nearby.

\subsection{Data analysis}

In the present study, an individual precipitation event was defined as a series of one or more consecutive days of rainfall followed by at least 1 day without rainfall.

We denoted GPP prior to the precipitation event as GPP base, which was averaged over three days before the event to better represent pre-rainfall GPP. Based on this, we evaluated the responses of GPP to an individual precipitation event in terms of its duration, maximum, and time-integrated amount: (1) the duration of GPP-response $\left(\tau_{\mathrm{R}}\right)$, which was calculated as the number of days required for GPP recovering its pre-precipitation event level of the $\mathrm{GPP}_{\text {base. }}$ If the daily GPP could not reach the $\mathrm{GPP}_{\text {base }}$ due to the occurrence of the next precipitation event, we would use a linear extrapolation method to estimate it; (2) the maximum absolute GPP increase (maximal magnitude of GPP increase; $\mathrm{GPP}_{\max }$ ) induced by the precipitation event, i.e. the maximal difference between daily GPP after rainfall and $\mathrm{GPP}_{\text {base}}$; and (3) the time-integrated amount of GPP-response (integrated total amount of GPP) during the response period (duration) $\left(\mathrm{GPP}_{\text {total }}\right) \cdot \mathrm{GPP}_{\text {total }}$ was computed with:

$$
\mathrm{GPP}_{\text {total }}=\sum_{i=1}^{\tau_{\mathrm{R}}}\left(\mathrm{GPP}_{\mathrm{i}}-\mathrm{GPP}_{\text {base }}\right) \text {. }
$$

Where $\tau_{\mathrm{R}}$ is the duration of GPP-response, and GPP $\mathrm{base}_{\text {is }}$ is the daily GPP before the precipitation event.

We also calculated the event-based precipitation use efficiency $\left(\mathrm{PUE}_{\mathrm{ev}}\right)$, which was the division of $\mathrm{GPP}_{\text {total }}$ by the size of the precipitation event. In addition, we evaluated the mean daily GPP-response to the precipitation event $\left(\mathrm{GPP}_{\text {mean }}\right)$, which was the division of GPP total by $\tau_{\mathrm{R}}$.

The GPP-response to an individual precipitation event may be confounded by other factors, e.g. soil water brought by previous rainfalls, leaf area, and photosynthetic capacity at different growth stages (Huxman et al., 2004a). To precisely evaluate the GPP-response to an individual precipitation event, several criteria should be satisfied for the selected precipitation events. Firstly, pre-rainfall SWC should be very low (mostly lower than the average SWC, i.e. $0.088 \mathrm{~cm}^{3} / \mathrm{cm}^{3}$ in this study) and the pre-inter-pulse period should be longer than 5 days to avoid the effects of the previous precipitation events that may shadow or confound the response of GPP to the precipitation event of interest. We did not evaluate the GPP-response during the middle or late growing season because the high precipitation frequency made it difficult to exclude the effects of the previous rainfall for most individual precipitation events. Secondly, the GPP-response to a certain size of precipitation event will vary with different leaf areas, hence, in order to eliminate the effects of leaf area, we normalized the GPP-response (i.e. $\mathrm{GPP}_{\max }, \mathrm{GPP}_{\text {total }}, \mathrm{GPP}_{\text {mean }}, \mathrm{PUE}_{\mathrm{ev}}$, but not $\tau_{\mathrm{R}}$ because $\tau_{\mathrm{R}}$ is mostly affected by the duration of SWC) with a division by leaf area index (LAI). LAI is evaluated by data of normalized difference vegetation index (NDVI) with models developed by $\mathrm{Hu}$ et al. (2009) $\left(\mathrm{LAI}=0.106 \mathrm{e}^{4.064 \mathrm{NDVI}}, R^{2}=0.94\right)$. NDVI data are from 
Moderate Resolution Imaging Spectroradiometer with 8-d time resolution and 250-m spatial resolution (MODIS, http://daac.ornl.gov/MODIS/modis.html). Finally, the response of GPP to a precipitation event may vary at different growth stages because of diverse photosynthetic capacities (there will be more response in the early growing season than in the late growing season), and for the comparison purpose we chose the neighboring precipitation events to minimize the possible effects of vegetation phenology. In total, six independent precipitation events from day of year (DOY) 155 to 188 were selected to make the correlation analysis (a 7.7, 40.2, and $21.9 \mathrm{~mm}$ precipitation event on DOY 155, 164, and 176 in 2012; a 4.7, 19.6, and $11 \mathrm{~mm}$ precipitation event on DOY 159, 168, and 188 in 2013). Hence, our results only reflected the GPP-response during the early growing season.

\section{Results}

\subsection{Dynamics of GPP after precipitation events}

The amount of precipitation during the periods of measurement (from DOY 137 to 262 in 2012 and from DOY 157 to 249 in 2013) was $275.5 \mathrm{~mm}$ in 2012 and $224.4 \mathrm{~mm}$ in 2013, respectively, and the total amount of GPP was $303.2 \mathrm{~g} \mathrm{C} / \mathrm{m}^{2}$ in 2012 and $289.8 \mathrm{~g} \mathrm{C} / \mathrm{m}^{2}$ in 2013 , respectively. GPP usually increased after precipitation events and also traced closely with the increase of soil water due to rainfalls (Fig. 1). Such time series of GPP variations triggered by precipitation pulses were more evident for the selected precipitation events (Fig. 2). GPP reached a peak 1-4 days after the pulses and then decreased to the pre-precipitation level till the next precipitation event. Although it varied with SWC in parallel, in some cases precipitation-triggered GPP changes lagged behind the changes of SWC which peaked usually about one day after the precipitation event.
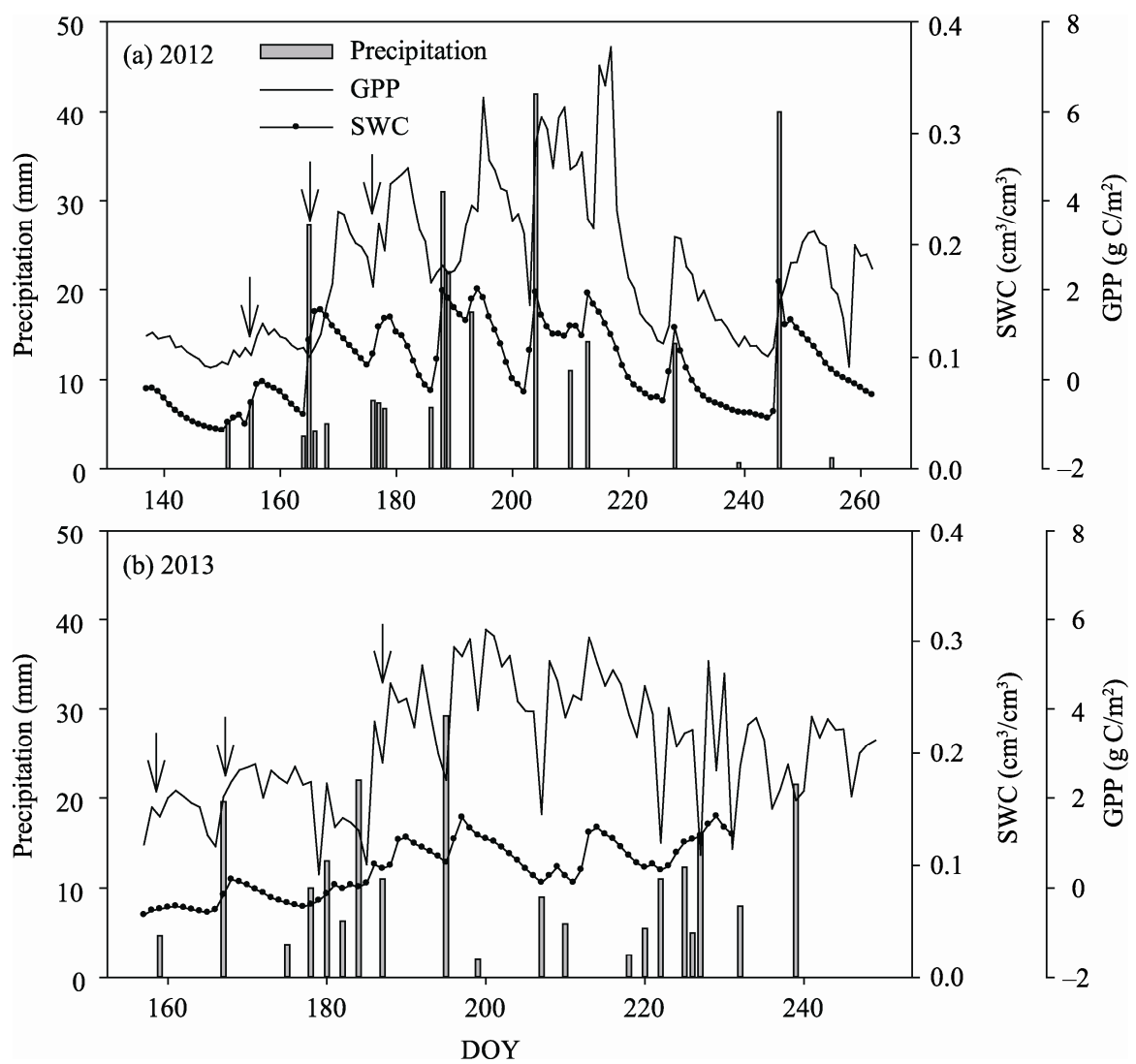

Fig. 1 Dynamics of daily GPP and SWC in 2012 and 2013 in a typical steppe in Inner Mongolia. The six precipitation events we selected were indicated by arrows above the precipitation event bars. GPP, gross primary productivity; SWC, soil water content; DOY, day of year. 

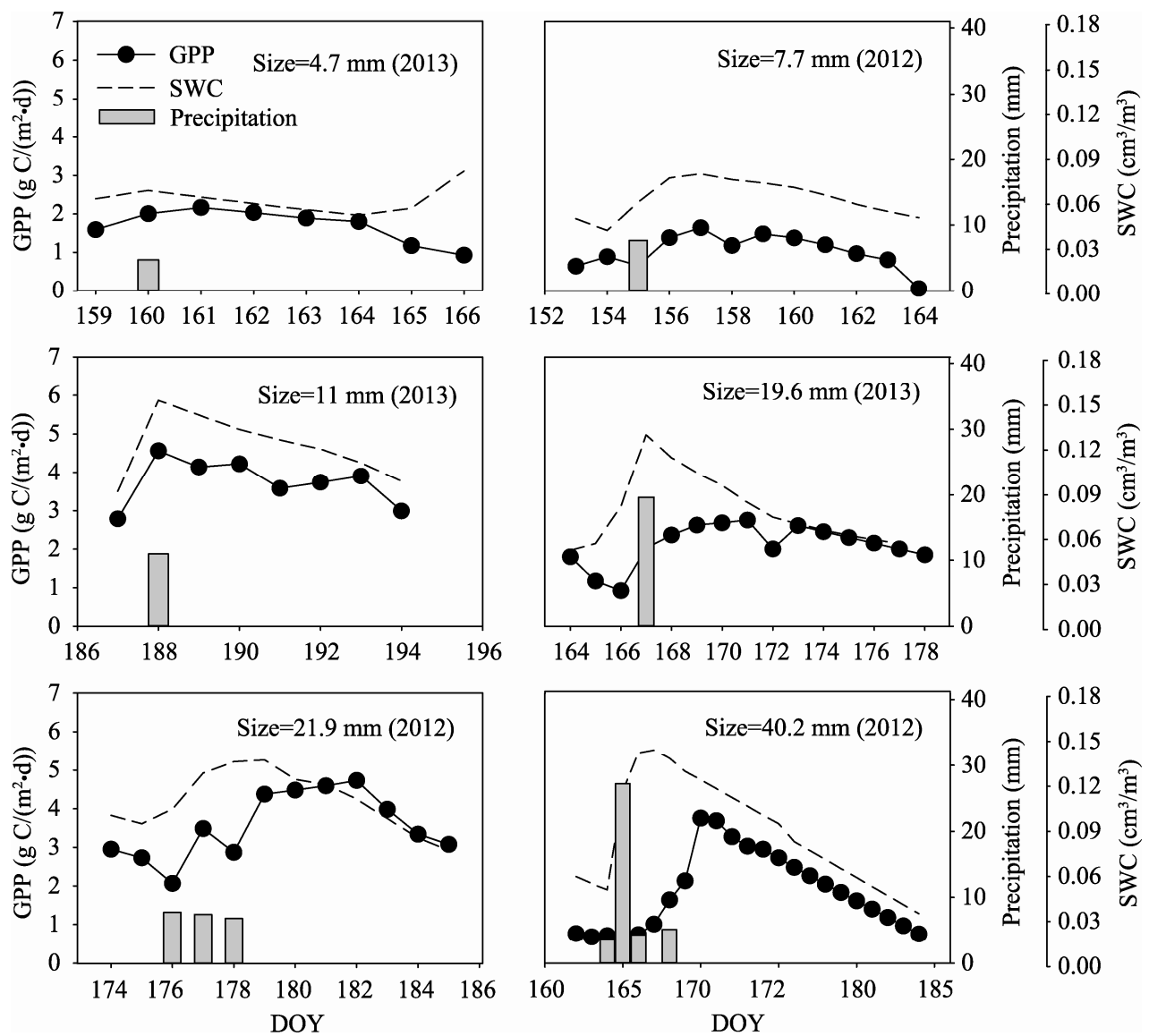

Fig. 2 Dynamics of daily GPP and SWC after different sizes of precipitation events in a typical steppe in Inner Mongolia. Rainfalls occurring for consecutive days were taken as one precipitation event (e.g. precipitation event with the size of $21.9 \mathrm{~mm}$ was composed of rainfalls during three consecutive days). All the subpanels have the same scaling for the $y$-axis of GPP, SWC, and precipitation.

\subsection{Responses of GPP to different sizes of precipitation events}

The duration of GPP-response $\left(\tau_{\mathrm{R}}\right)$ to an individual precipitation event, the maximum absolute GPP increase induced by the event $\left(\mathrm{GPP}_{\max }\right)$, and the time-integrated amount of GPP during the response period $\left(\mathrm{GPP}_{\text {total }}\right)$ all presented a linear increase with the sizes of precipitation events $\left(P_{\mathrm{es}}\right)$. When the precipitation event size ranged from 4.7 to $40.2 \mathrm{~mm}$ in the steppe studied, $\tau_{\mathrm{R}}$ ranged from 5 to $18 \mathrm{~d}$ (Fig. 3a), the $\mathrm{GPP}_{\max }$ varied from 1.4 to $6.4 \mathrm{~g} \mathrm{C} /\left(\mathrm{m}^{2} \cdot \mathrm{d}\right)$ (Fig. 3b), and $\mathrm{GPP}_{\text {total }}$ increased from 2.0 to $53.8 \mathrm{~g} \mathrm{C} / \mathrm{m}^{2}$ (Fig. 3c), respectively. The mean of GPP-response to the precipitation event $\left(\mathrm{GPP}_{\text {mean }}\right)$ varied from 0.4 to $3.0 \mathrm{~g} \mathrm{C} /\left(\mathrm{m}^{2} \cdot \mathrm{d}\right)$ (Fig. 3d).

There was a significantly linear relationship between the $\mathrm{GPP}_{\text {total }}$ and $P_{\text {es }}$ (Fig. 3c). From this relationship we could identify a critical value for $P_{\mathrm{es}}$, above which the real response of GPP happened, i.e. $\mathrm{GPP}_{\text {total }}>0$. According to the regression equation $\left(\mathrm{GPP}_{\text {total }}=1.38 P_{\mathrm{es}}-7.06\right)$, a size of precipitation larger than $5 \mathrm{~mm}$ at least was needed to stimulate the increase of GPP after rainfall in this steppe, i.e. the ecologically effective precipitation event. In addition, the event-based precipitation use efficiency ( $\mathrm{PUE}_{\mathrm{ev}}$; Fig. 4) also increased linearly with increasing $P_{\mathrm{es}}$, but the regression was only marginally significant $(P=0.06)$.

The time-integrated amount of GPP-response to a precipitation event was determined by the response period (duration) and the maximum absolute GPP increase induced by the precipitation event $\left(\mathrm{GPP}_{\max }\right.$, relative to the $\left.\mathrm{GPP}_{\text {base }}\right)$. We described this using a covariate multiple linear regression with a very high coefficient of determination:

$$
\mathrm{GPP}_{\text {total }}=2.43 \mathrm{GPP}_{\max }+2.43 \tau_{\mathrm{R}}-0.76 \mathrm{GPP}_{\max } \times \tau_{\mathrm{R}}-3.65 . \quad\left(n=6, R^{2}=0.99, P<0.001\right) \text {. }
$$


The stepwise regression analysis showed that $\tau_{\mathrm{R}}$ explained $47.2 \%$ of the variations of $\mathrm{GPP}_{\text {total }}$, which was comparable to the explanatory power of $\mathrm{GPP}_{\max }(49.8 \%)$. However, the GPP total was mostly determined by the GPP $\max _{\max }$ when $P_{\text {es }}$ was relatively small (e.g. $<10 \mathrm{~mm}$ ), whereas the $\mathrm{GPP}_{\text {total }}$ was mainly determined by the GPP-response period when $P_{\text {es }}$ was relatively large (Fig. 5).
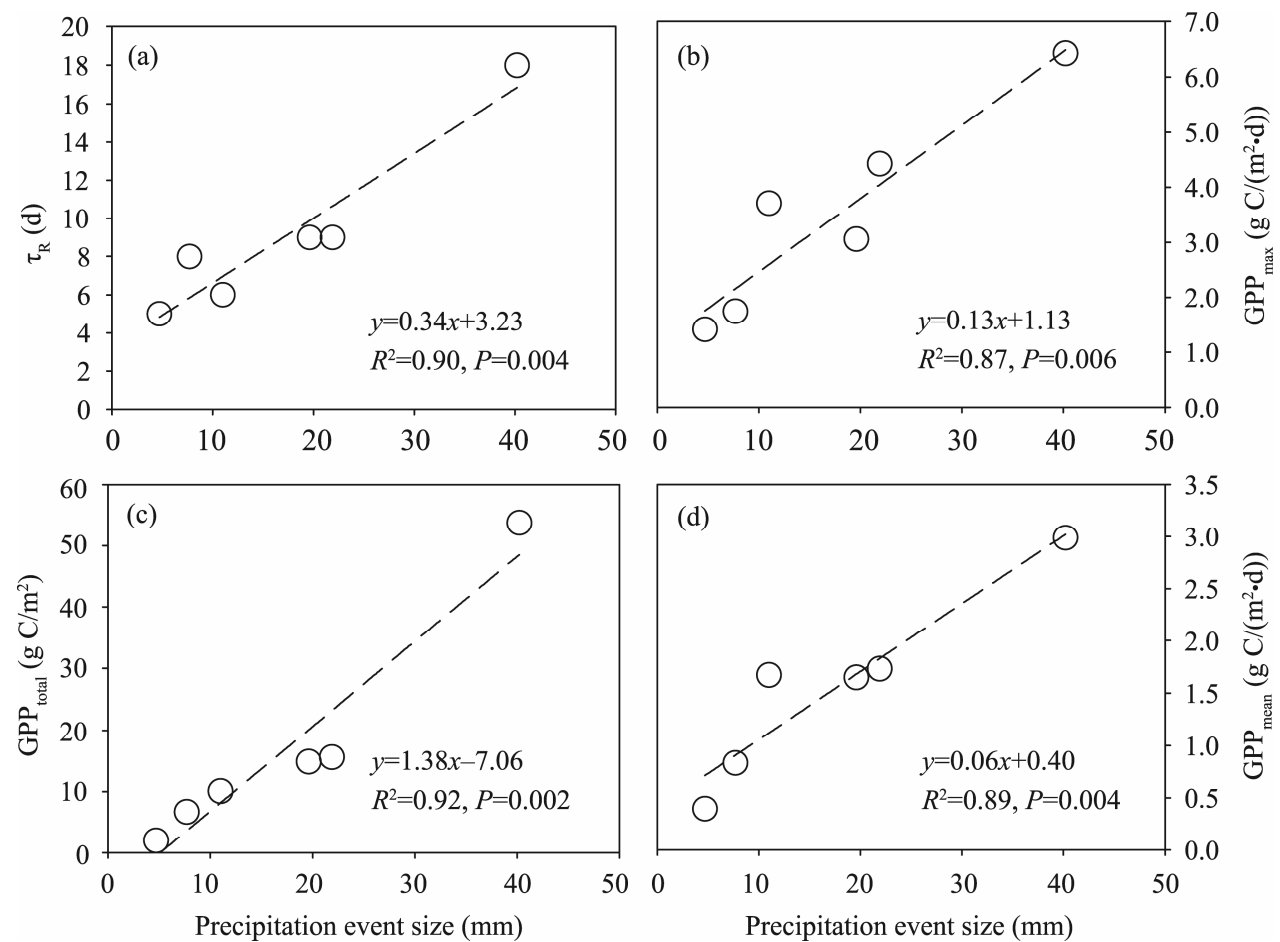

Fig. 3 The variations of the duration of GPP-response $\left(\tau_{\mathrm{R}}\right)$ to a precipitation event (a), the maximum absolute GPP increase $\left(\mathrm{GPP}_{\max }\right)$ induced by the event $(\mathrm{b})$, the time-integrated amount of GPP $\left(\mathrm{GPP}_{\text {total }}\right)$ during the response period (c), and the mean daily GPP (GPP mean $)$ since the event (d) along sizes of precipitation events in a temperate steppe in Inner Mongolia.

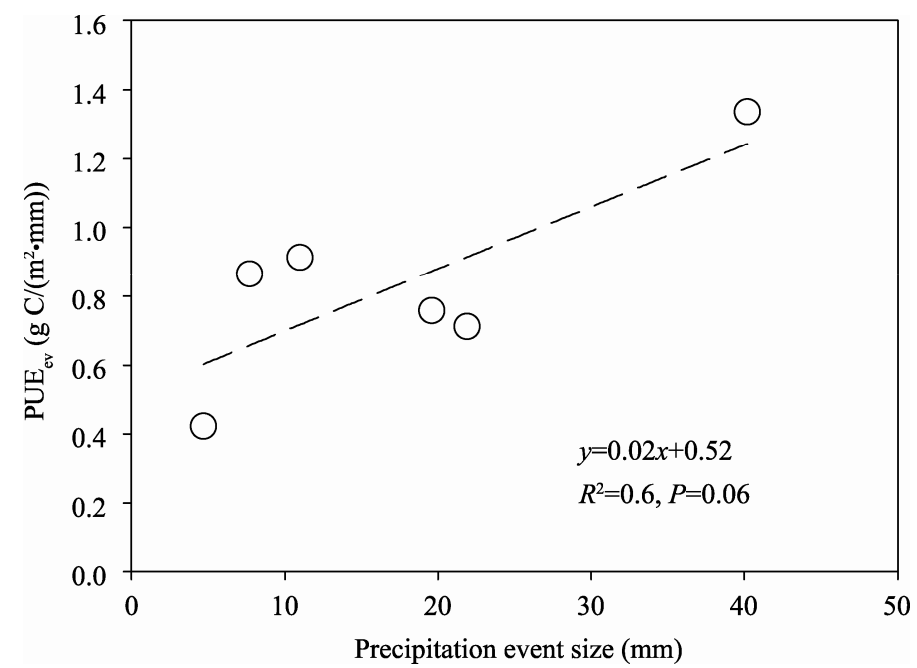

Fig. 4 The variations of the event-based precipitation use efficiency ( $\mathrm{PUE}_{\mathrm{ev}}$ ) along sizes of precipitation events $\left(P_{\mathrm{es}}\right)$ in a temperate steppe in Inner Mongolia. $\mathrm{PUE}_{\mathrm{ev}}$ was calculated as the division of the time-integrated amount of GPP-response by $P_{\mathrm{es}}$. 


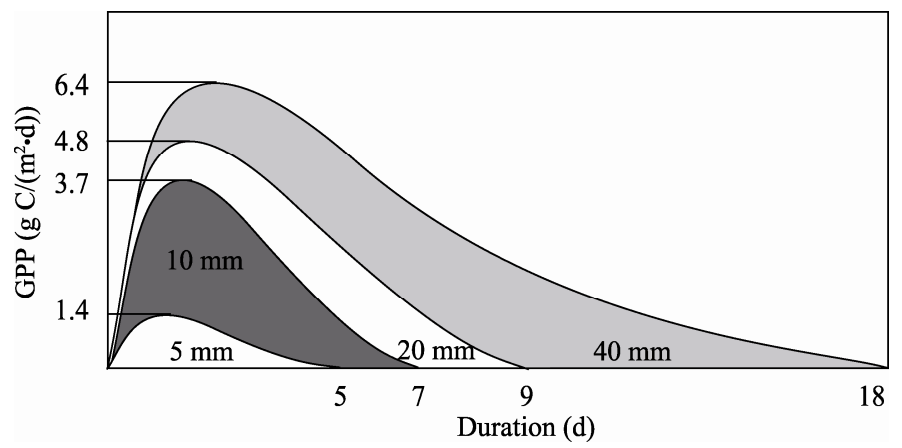

Fig. 5 A conceptual illustration of the time course (duration) of GPP-response to different sizes of precipitation events. The $x$-axis (day since the precipitation event) shows the length of time period (duration) of GPP-response, and the $y$-axis indicates the temporal change of GPP-response magnitude. The dark gray area implies that the increase of the time-integrated amount of GPP-response to the precipitation event from 5 to $10 \mathrm{~mm}$ was mainly from the increase of the maximum absolute GPP-response, while the light gray area implies that the increase of the time-integrated amount of GPP-response to the precipitation event from 20 to $40 \mathrm{~mm}$ was mainly dependent on the increase of GPP-response period.

\section{Discussion}

The GPP-response to an individual precipitation event increased linearly with the increasing sizes of precipitation events $\left(P_{\mathrm{es}}\right)$ in terms of duration $\left(\tau_{\mathrm{R}}\right)$, maximum $\left(\mathrm{GPP}_{\max }\right)$ and time-integrated amount $\left(\mathrm{GPP}_{\text {total }}\right)$. Our results are consistent with a conceptual response of productivity to a single rainfall, in which a linear relationship was employed when precipitation event size was between the low-limit and up-limit of the productivity-response (Huxman et al., 2004a). The positive relationship between GPP-response and $P_{\text {es }}$ is mostly due to the corresponding responses of soil moisture to $P_{\text {es. }}$. Most previous studies have showed that productivity of the temperate steppe in Inner Mongolia was primarily constrained by water availability (Hu et al., 2007, 2010; Bai et al., 2008). Moreover, the duration and amount of SWC also positively responded to $P_{\mathrm{es}}$ (the correlation coefficients between $P_{\mathrm{es}}$ and the duration and amount of SWC was 0.84 and 0.90 , respectively in this study, data not shown), which is also consistent with previous studies (He et al., 2012). Higher SWC after heavier precipitation and thus higher photosynthesis (Liu et al., 2012) led to corresponding higher GPP-response. However, there might be an upper limit of $P_{\text {es }}$ for the increase of GPP-response, above which other factors, e.g. plant photosynthetic capacity, leaf area, and soil nutrient content, might play a critical role (Hu et al., 2008; Li et al., 2008; Zhang et al., 2013). For example, a study in arid and sub-humid ecosystems indicated that plant photosynthesis did not vary much when soil water content after rainfall reached to a critical level and the ecosystems were instead limited by soil nitrogen availability (Yandjian et al., 2011).

The event-based precipitation use efficiency $\left(\mathrm{PUE}_{\mathrm{ev}}\right)$ was positively related to $P_{\mathrm{es}}$ with marginal significance, suggesting that the relationship between $\mathrm{GPP}_{\text {total }}$ and $P_{\text {es }}$ was not a simple linear function. The increasing trend of $\mathrm{PUE}_{\mathrm{ev}}$ along $P_{\mathrm{es}}$ may be partly due to the vertical distribution of SWC after rainfalls. It has been reported that small precipitation events only affected SWC in surface soil but that heavy ones affected the deeper soil layers (Kurc and Small, 2007; He et al., 2012; Lauenroth and Bradford, 2012). Moreover, studies also have reported that there were remarkably positive correlations between soil evaporation and surface SWC and between plant transpiration and deeper SWC (Yepez et al., 2005). Taking account into the low vegetation cover but high evaporative demand in the temperate steppe in Inner Mongolia, precipitation of small sizes would be mostly returned to the atmosphere through soil evaporation, whereas precipitation of large sizes would be more effectively taken up by plants (Knapp et al., 2008), i.e. higher $\mathrm{PUE}_{\mathrm{ev}}$ after heavier precipitation. Therefore, when our regression between GPP-response and $P_{\text {es }}$ is used to model the GPP-response under altering precipitation event sizes, we should be cautious for two reasons. Firstly, the sample size of this study is relatively small, and there are no extreme precipitation events larger than $40 \mathrm{~mm}$ in reality in the study area. 
According to the positive $\mathrm{PUE}_{\mathrm{ev}}-P_{\text {es }}$ relationship (implying an increasing rate of GPP-response along $P_{\mathrm{es}}$ ), an exponential relationship between $\mathrm{GPP}_{\text {total }}$ and $P_{\mathrm{es}}$ is likely more rational with more observations incorporated. Secondly, the regression may be ecosystem specific. The effects of species composition or soil texture on the GPP-response to an individual precipitation event should not be ignored (Austin et al., 2004; Huxman et al., 2004b). For example, a study in the grassland of Argentina showed that responses of productivity to precipitation differed between shrubs and herbaceous plants (Jobbágy and Sala, 2000). Hence, our results may only reflect the responses of GPP to precipitation events for temperate steppes.

Although $\mathrm{GPP}_{\text {total }}$ could be well characterized jointly by $\tau_{\mathrm{R}}$ and $\mathrm{GPP}_{\max }$, the relative contributions of $\tau_{\mathrm{R}}$ and GPP $\mathrm{Gax}_{\max }$ were evidently depended on $P_{\text {es }}$. When $P_{\text {es }}$ was relatively small, the $\mathrm{GPP}_{\max }$ contributed more to the variation of GPP $\mathrm{Gtal}_{\text {tal }}$ than to that of $\tau_{\mathrm{R}}$; whereas, when $P_{\mathrm{es}}$ was relatively large, the reverse held true. Previous studies demonstrated that GPP-response started at an around 5-mm threshold of $P_{\mathrm{es}}$ in a typical steppe in Inner Mongolia (Hao et al., 2010, 2012; Zhang et al., 2013), which is very close to the threshold value in the present study. Obviously, precipitation events below this threshold could not trigger a detectable GPP-response, and thus GPP was substantially constrained by soil moisture status when $P_{\text {es }}$ was relative small. As $P_{\text {es }}$ increased, the soil water limitation was largely alleviated and thus there would be a large increase of productivity (i.e. large $\mathrm{GPP}_{\max }$ ), whereas the increase of the duration of SWC-response at this size of precipitation was relatively small. Therefore, the increase of $\mathrm{GPP}_{\text {total }}$ was mainly induced from the increase of GPP $\mathrm{max}_{\text {. }}$ As $P_{\mathrm{es}}$ kept increasing, we argued that the maximum absolute GPP-response was most likely determined by the photosynthetic capacity and leaf area (responded slowly to the increasing soil moisture), and $\mathrm{GPP}_{\max }$ thus did not vary much. Moreover, $\tau_{\mathrm{R}}$ was more modulated by $P_{\mathrm{es}}$, i.e. the larger $P_{\mathrm{es}}$, the longer $\tau_{\mathrm{R}}$, and the larger $\mathrm{GPP}_{\text {total }}$ would be as well. This implies that $\tau_{\mathrm{R}}$ is more important when $P_{\mathrm{es}}$ is considerably large.

\section{Conclusions}

In this study, we quantified the duration, the maximum, and the time-integrated amount of the response of GPP ( $\left.\mathrm{GPP}_{\text {total }}\right)$ to an individual precipitation event and their variations with different sizes of precipitation events $\left(P_{\mathrm{es}}\right)$ in a typical temperate steppe in Inner Mongolia, China. We found that $\mathrm{GPP}_{\text {total }}$ increased with $P_{\mathrm{es}}$. The variations in $\mathrm{GPP}_{\text {total }}$ were largely explained by the GPP-response duration $\left(\tau_{\mathrm{R}}\right)$ and the maximum absolute GPP-response $\left(\mathrm{GPP}_{\max }\right)$ after the precipitation event. However, the relative importance of $\tau_{\mathrm{R}}$ and $\mathrm{GPP}_{\max }$ to $\mathrm{GPP}_{\text {total }}$ varied with $P_{\mathrm{es}}$. Clearly, our study may provide an insight into how GPP of the steppe ecosystem responds to altering precipitation regimes. However, the GPP-response to precipitation receives influences from a variety of other abiotic and biotic factors; therefore, further studies under different climate conditions and ecosystem types are needed to better characterize GPP-response to individual precipitation events. In particular, further endeavor is also required to clarify the dynamics of the GPP-response to precipitation within and across plant growing seasons.

\section{Acknowledgements}

This study was jointly supported by the National Natural Science Foundation of China (31400425, 31570437, 41301043, 31420103917), the National Key Project of Scientific and Technical Supporting Program (2013BAC03B03), the Funding for Talented Young Scientists of IGSNRR (2013RC203), and the Social Foundation of Beijing Academy of Social Sciences (154005). We would like to thank Dr. ZHANG Leiming and Dr. ZHU Mengxun for their help in field observation and data processing.

\section{References}

Austin A T, Yahdjian L, Stark J M, et al. 2004. Water pulses and biogeochemical cycles in arid and semiarid ecosystems. Oecologia, 141(2): 221-235.

Bai Y F, Wu J G, Xing Q, et al. 2008. Primary production and rain use efficiency across a precipitation gradient on the Mongolia Plateau. Ecology, 89(8): 2140-2153. 
Beier C, Beierkuhnlein C, Wohlgemuth T, et al. 2012. Precipitation manipulation experiments--challenges and recommendations for the future. Ecology Letters, 15(8): 899-911.

Chen S P, Lin G H, Huang J H, et al. 2009. Dependence of carbon sequestration on the differential responses of ecosystem photosynthesis and respiration to rain pulses in a semiarid steppe. Global Change Biology, 15(10): 2450-2461.

Cherwin K, Knapp A. 2012. Unexpected patterns of sensitivity to drought in three semi-arid grasslands. Oecologia, 169(3): $845-852$.

Easterling D R, Meehl G A, Parmesan C, et al. 2000. Climate extremes: Observations, modeling, and impacts. Science, 289(5487): 2068-2074.

FAO. 1974. Soil Map of the World 1:5,000,000. Volumes 1-10. Paris: Food and Agriculture Organization of the United Nations and UNESCO.

Fay P A, Carlisle J D, Knapp A K, et al. 2003. Productivity responses to altered rainfall patterns in a $\mathrm{C}_{4}$-dominated grassland. Oecologia, 137(2): 245-251.

Hao Y B, Wang Y F, Mei X R, et al. 2010. The response of ecosystem $\mathrm{CO}_{2}$ exchange to small precipitation pulses over a temperate steppe. Plant Ecology, 209(2): 335-347.

Hao Y B, Kang X M, Cui X Y, et al. 2012. Verification of a threshold concept of ecologically effective precipitation pulse: From plant individuals to ecosystem. Ecological Informatics, 12: 23-30.

Harper C W, Blair J M, Fay P A, et al. 2005. Increased rainfall variability and reduced rainfall amount decreases soil $\mathrm{CO}_{2}$ flux in a grassland ecosystem. Global Change Biology, 11(2): 322-334.

He Z B, Zhao W Z, Liu H, et al. 2012. The response of soil moisture to rainfall event size in subalpine grassland and meadows in a semi-arid mountain range: A case study in northwestern China's Qilian Mountains. Journal of Hydrology, 420-421: 183-190.

Heisler-White J L, Knapp A K, Kelly E F. 2008. Increasing precipitation event size increases aboveground net primary productivity in a semi-arid grassland. Oecologia, 158(1): 129-140.

Heisler-White J L, Blair J M, Kelly E F, et al. 2009. Contingent productivity responses to more extreme rainfall regimes across a grassland biome. Global Change Biology, 15(12): 2894-2904.

Hu Z M, Fan J W, Zhong H P, et al. 2007. Spatiotemporal dynamics of aboveground primary productivity along a precipitation gradient in Chinese temperate grassland. Science in China Series D: Earth Sciences, 50(5): 754-764.

Hu Z M, Yu G R, Fu Y L, et al. 2008. Effects of vegetation control on ecosystem water use efficiency within and among four grassland ecosystems in China. Global Change Biology, 14(7): 1609-1619.

Hu Z M, Yu G R, Zhou Y L, et al. 2009. Partitioning of evapotranspiration and its controls in four grassland ecosystems: Application of a two-source model. Agricultural and Forest Meteorology, 149(9): 1410-1420.

$\mathrm{Hu}$ Z M, Yu G R, Fan J W, et al. 2010. Precipitation-use efficiency along a 4500-km grassland transect. Global Ecology and Biogeography, 19(6): 842-851.

Huang G, Li Y, Padilla F M. 2015. Ephemeral plants mediate responses of ecosystem carbon exchange to increased precipitation in a temperate desert. Agricultural and Forest Meteorology, 201: 141-152.

Huxman T E, Snyder K A, Tissue D, et al. 2004a. Precipitation pulses and carbon fluxes in semiarid and arid ecosystems. Oecologia, 141(2): 254-268.

Huxman T E, Cable J M, Ignace D D, et al. 2004b. Response of net ecosystem gas exchange to a simulated precipitation pulse in a semi-arid grassland: the role of native versus non-native grasses and soil texture. Oecologia, 141(2): 295-305.

Intergovernmental Panel on Climate Change (IPCC). 2013. Long-term Climate Change: Projections, Commitments and Irreversibility. In: Climate Change 2013: The Physical Science Basis. Contribution of Working Group I to the Fifth Assessment Report of the Intergovernmental Panel on Climate Change. Cambridge, United Kingdom and New York, USA: Cambridge University Press.

Jobbágy E G, Sala O E. 2000. Controls of grass and shrub aboveground production in the Patagonian steppe. Ecological Applications, 10(2): 541-549.

Knapp A K, Fay P A, Blair J M, et al. 2002. Rainfall variability, carbon cycling, and plant species diversity in a mesic grassland. Science, 298(5601): 2202-2205.

Knapp A K, Beier C, Briske D D, et al. 2008. Consequences of more extreme precipitation regimes for terrestrial ecosystems. BioScience, 58(9): 811-821.

Kurc S A, Small E E. 2007. Soil moisture variations and ecosystem-scale fluxes of water and carbon in semiarid grassland and shrubland. Water Resources Research, 43(6): W06416.

Lauenroth W K, Bradford J B. 2012. Ecohydrology of dry regions of the United States: water balance consequences of small precipitation events. Ecohydrology, 5(1): 46-53. 
Li F, Zhao W Z, Liu H. 2013. The response of aboveground aboveground net primary productivity of desert vegetation to rainfall pulse in the temperate desert region of northwest China. PLoS ONE, 8(9): e73003.

Li X J, Li X R, Song W M, et al. 2008. Effects of crust and shrub patches on runoff, sedimentation, and related nutrient (C, N) redistribution in the desertified steppe zone of the Tengger Desert, Northern China. Geomorphology, 96(1-2): 221-232.

Li X R, Ma F Y, Long L Q, et al. 2001. Soil water dynamics under sand-fixing vegetation in shapotou area. Journal of Desert Research, 21(3): 217-222. (in Chinese)

Liang N S, Inoue G, Fujinuma Y. 2003. A multichannel automated chamber system for continuous measurement of forest soil $\mathrm{CO}_{2}$ efflux. Tree Physiology, 23(12): 825-832.

Liu B, Zhao W Z, Wen Z J. 2012. Photosynthetic response of two shrubs to rainfall pulses in desert regions of northwestern China. Photosynthetica, 50(1): 109-119.

Lloyd J, Taylor J A. 1994. On the temperature dependence of soil respiration. Functional Ecology, 8(3): 315-323.

Loik M E, Breshears D D, Lauenroth W K, et al. 2004. A multi-scale perspective of water pulses in dryland ecosystems: climatology and ecohydrology of the western USA. Oecologia, 141(2): 269-281.

Parton W, Morgan J, Smith D, et al. 2012. Impact of precipitation dynamics on net ecosystem productivity. Global Change Biology, 18(3): 915-927.

Reichstein M, Tenhunen J D, Roupsard O, et al. 2002. Ecosystem respiration in two Mediterranean evergreen Holm Oak forests: drought effects and decomposition dynamics. Functional Ecology, 16(1): 27-39.

Ross I, Misson L, Rambal S, et al. 2012. How do variations in the temporal distribution of rainfall events affect ecosystem fluxes in seasonally water-limited Northern Hemisphere shrublands and forests? Biogeosciences, 9: 1007-1024.

Swemmer A M, Knapp A K, Snyman H A. 2007. Intra-seasonal precipitation patterns and above-ground productivity in three perennial grasslands. Journal of Ecology, 95(4): 780-788.

Tan Z H, Zhang Y P, Liang N S, et al. 2013. Soil respiration in an old-growth subtropical forest: Patterns, components, and controls. Journal of Geophysical Research: Atmospheres, 118(7): 2981-2990.

Thomey M L, Collins S L, Vargas R, et al. 2011. Effect of precipitation variability on net primary production and soil respiration in a Chihuahuan Desert grassland. Global Change Biology, 17(4): 1505-1515.

Walter J, Grant K, Beierkuhnlein C, et al. 2012. Increased rainfall variability reduces biomass and forage quality of temperate grassland largely independent of mowing frequency. Agriculture, Ecosystems \& Environment, 148: 1-10.

Xia J Y, Niu S L, Ciais P, et al. 2015. Joint control of terrestrial gross primary productivity by plant phenology and physiology. Proceedings of the National Academy of Sciences of the United States of America, 112(9): 2788-2793.

Yandjian L, Gherardi L, Sala O E. 2011. Nitrogen limitation in arid-subhumid ecosystems: A meta-analysis of fertilization studies. Journal of Arid Environments, 75(8): 675-680.

Yepez E A, Huxman T E, Ignace D D, et al. 2005. Dynamics of transpiration and evaporation following a moisture pulse in semiarid grassland: A chamber-based isotope method for partitioning flux components. Agricultural and Forest Meteorology, 132(3-4): 359-376.

Zeppel M J B, Wilks J V, Lewis J D. 2014. Impacts of extreme precipitation and seasonal changes in precipitation on plants. Biogeosciences, 11: 3083-3093.

Zhang B C, Cao J J, Bai Y F, et al. 2013. Effects of rainfall amount and frequency on vegetation growth in a Tibetan alpine meadow. Climatic Change, 118(2): 197-212.

Zhang Y G, Moran M S, Nearing M A, et al. 2013. Extreme precipitation patterns and reductions of terrestrial ecosystem production across biomes. Journal of Geophysical Research: Biogeosciences, 118(1): 148-157. 